\title{
Ticks (Acari: Ixodidae) infesting cattle and African buffaloes in the Tsavo conservation area, Kenya
}

\begin{abstract}
Authors:
Edward K. Kariuki ${ }^{1,2}$

Barend L. Penzhorn²

Ivan G. Horak ${ }^{2}$

Affiliations:

${ }^{1}$ Department of Veterinary and Capture Services, Kenya

Wildlife Service, Kenya

${ }^{2}$ Department of Veterinary Tropical Diseases, University of Pretoria, South Africa

Correspondence to: Ivan Horak

Email:

ivan.horak@up.ac.za

Postal address:

Private Bag X04,

Onderstepoort 0110,

South Africa

Dates:

Received: 10 Apr. 2012

Accepted: 22 Aug. 2012

Published: 21 Nov. 2012

How to cite this article: Kariuki, E.K., Penzhorn, B.L. \& Horak, I.G., 2012, 'Ticks (Acari: Ixodidae) infesting cattle and African buffaloes in the Tsavo conservation area, Kenya', Onderstepoort Journal of Veterinary Research 79(1), Art. \#437, 4 pages. http:// dx.doi.org/10.4102/ojvr. v79i1.437
\end{abstract}

C 2012. The Authors. Licensee: AOSIS OpenJournals. This work is licensed under the Creative Commons Attribution License.
Several ixodid tick species are shared between domestic cattle and African buffaloes (Syncerus caffer). So too, are a number of tick-borne diseases. The aim of the study was to compare the species composition of ticks that infest cattle and buffaloes utilising the same habitat within the Tsavo Conservation Area, Kenya. To this end, 25 cattle and 62 buffaloes were each opportunistically sampled for ticks on a single occasion in February 2010. Eight species, namely Amblyomma gemma, Amblyomma lepidum, Hyalomma albiparmatum, Hyalomma rufipes, Hyalomma truncatum, Rhipicephalus evertsi evertsi, Rhipicephalus pravus and Rhipicephalus pulchellus infested both cattle and buffaloes. Three species, Rhipicephalus (Boophilus) sp., Rhipicephalus kochi, and Rhipicephalus muehlensi were collected only from cattle, and three species, Hyalomma impeltatum, Rhipicephalus humeralis and Rhipicephalus praetextatus were present only on buffaloes. The attachment sites of the various tick species were also recorded. New locality records for H. impeltatum and H. truncatum and the first confirmed locality record for Rhipicephalus praetextatus sensu stricto in Kenya were documented.

\section{Communication}

The adults of a large number of ixodid tick species infest both domestic cattle and African buffaloes (Syncerus caffer) in Kenya as well as elsewhere in Africa (Horak 1999; Horak, Golezardy \& Uys 2007; Londt, Horak \& De Villiers 1979; Walker 1974). Several of these tick species are vectors of disease, but whereas buffaloes are seldom affected by tick-borne diseases, they can have devastating effects on cattle. The two most noteworthy of these diseases are heartwater, caused by Ehrlichia ruminantium and transmitted by certain Amblyomma species and East Coast fever and Corridor disease, caused by Theileria parva and transmitted by Rhipicephalus appendiculatus (Allsopp, Bezuidenhout \& Prozesky 2004; Lawrence, Perry \& Williamson 2004).

Although the tick species that infest cattle and African buffaloes in Kenya and in the Eastern Cape Province of South Africa have been meticulously recorded (Horak 1999; Horak et al. 2007; Walker 1974), to our knowledge no surveys have been done on the ticks that occur on these animals in a common habitat. Moreover, the ticks infesting cattle and wildlife in Kenya and their geographic distributions were last reviewed in the 1960s (Walker 1974). Since then, vegetation cover and farming practices have undergone several changes, and tick species diversity and distribution have probably also changed in response to these events.

The objectives of the present study were to identify and compare the species of ticks that infest cattle and African buffaloes sharing the same habitat within the greater Tsavo Conservation Area in south-eastern Kenya. The predilection attachment sites of adult ticks on the two host species were also recorded.

The survey was conducted in the Tsavo East and Tsavo West National Parks and the privately owned Taita ranches and human settlement areas which form a partial corridor between the parks in the south-east. Since the parks are not fenced, most cattle utilise the park's pastures during the dry seasons, with their owners finding themselves in the parks without intent, or deliberately entering them in search of fresh pastures. On the other hand, the ranches, numbering approximately 20, constitute a vital dispersal area for wildlife. The parks and ranches comprise the greater Tsavo Conservation Area, which lies between $04.20^{\circ} \mathrm{S}, 37.65^{\circ} \mathrm{E}$ and $01.92^{\circ} \mathrm{S}, 39.36^{\circ} \mathrm{E}$ in the south-east of Kenya and borders on Tanzania in the south. The vegetation of the parks comprises open plains alternating from grasslands and bushlands to semi-arid acacia shrub and woodlands (Tolvanen 2004).

During February 2010 a single opportunistic collection of ticks was made from individual cattle at a community cattle dip-tank at Bachuma (an area adjacent to the Tsavo East National Park), and from a small herd of cattle held at the Maktau gate of Tsavo West National Park because of illegal entry into the park, as well as from individual animals at other randomly distributed 
localities. A total of 25 cattle were sampled in this way. All these animals had been subjected to weekly spraying with an acaricide. In the same month, ticks were also collected opportunistically from each of 62 immobilised African buffaloes during a rinderpest surveillance campaign within the Tsavo Conservation Area.

Tick collection was done by hand or with forceps from six sites on each animal (one ear, one side of the neck, one leg including the foot, the whole tail including the tail brush, the whole upper perineum, and one half of the lower perineum). Ticks from each body region of each animal were first placed separately in bijou bottles containing Boardman's solution (80\% water, $3 \%$ di-ethyl ether and $17 \%$ alcohol) in order to kill them. They were removed from the solution after 24 hours and placed in vials containing a long-term preservative $(80 \%$ alcohol, $14 \%$ water and $5 \%$ glycerol to which $1 \%$ chloroform was added to preserve their colour). Identification labels were written in pencil and placed in the sample bottles with the ticks in order to ensure correct identification of the samples.

Tick identification and counting were done using a stereoscopic microscope. Taxonomic descriptions and illustrations were used as aids towards identification (Walker 1960; Walker \& Olwage 1987; Walker, Keirans \& Horak 2000). Ticks whose identity could not be determined, were sent to the Department of Veterinary Tropical Diseases, University of Pretoria, for identification.

The species and numbers of ticks collected from cattle and buffaloes in the Tsavo Conservation Area are summarised in Tables 1 and 2. A total of 14 ixodid tick species were collected from the cattle and buffaloes and 8 of these species infested both hosts. Rhipicephalus (Boophilus) sp., Rhipicephalus kochi and Rhipicephalus muehlensi were present only on cattle, and Hyalomma impeltatum, Rhipicephalus humeralis and Rhipicephalus praetextatus were collected only from buffaloes.

The results indicate that a large number of tick species, of which the adults may infest cattle and/or buffaloes, are present in the Tsavo Conservation Area. Walker (1974) recorded 14 such species in this region. Three of the species mentioned by Walker (1974), namely Amblyomma variegatum, $R$. appendiculatus and Rhipicephalus maculatus were not collected in this survey. The absence of $A$. variegatum, a major vector of E. ruminantium and $R$. appendiculatus, the vector of T. parva, on the 87 animals currently sampled, begs further investigation in the light of Walker's earlier survey.

In the present survey the proportions of cattle and buffaloes infested with Amblyomma gemma were similar, as were the proportions infested with Amblyomma lepidum. Both ticks are potential vectors of E. ruminatium, but are not regarded as playing a significant role in its transmission in the field (Allsopp et al. 2004; Walker \& Olwage 1987). Amblyomma gemma was collected from the neck of cattle and from the leg, upper and lower perineum and tail of both cattle and buffaloes, whilst A. lepidum was collected from the neck, leg and lower perineum. These attachment sites largely agree with those of Yeoman and Walker (1967) and Walker (1974), who recorded the ventral surface of the body from the dewlap and axilla to the escutcheon as preferred attachment sites for these ticks.

Four Hyalomma species were collected in this study. Two of the 25 cattle examined were infested with Hyalomma albiparmatum and six of the 62 buffaloes. Walker (1974) recorded 30 collections of this tick from cattle and none from buffaloes. Ticks were collected from the tail and tailbrush of cattle, and from the tail and lower perineum of buffaloes, the same sites as those reported by Walker (1974). Few collections of $H$. impeltatum have been reported from Kenya and none from the region of the Tsavo Conservation Area (Walker 1974). The collection of three ticks from the lower perineum of a single buffalo at this locality thus constitutes a new locality record. No ticks belonging to this species were collected from cattle.

Walker (1974) lists 25 confirmed records of collections of Hyalomma rufipes from cattle in Kenya and five from buffaloes. In this survey, six cattle and 31 buffaloes were infested and ticks were recovered from the upper perineum and tail of cattle and from the ears, legs, lower perineum and the tail of buffaloes. These attachment sites agree with those recorded by Londt et al. (1979). Walker (1974) reports 31 confirmed records of Hyalomma truncatum in 892 collections from cattle

TABLE 1: Ticks collected from cattle in the Tsavo Conservation Area, Kenya.

\begin{tabular}{lllll}
\hline Tick species & Males & Females & Total & $\begin{array}{l}\text { Proportion } \\
\text { of animals } \\
\text { infested (\%) }\end{array}$ \\
\hline Amblyomma gemma & 68 & 53 & 121 & 56 \\
Amblyomma lepidum & 6 & 5 & 11 & 28 \\
Hyalomma albiparmatum & 4 & 2 & 6 & 8 \\
Hyalomma rufipes & 4 & 9 & 13 & 24 \\
Hyalomma truncatum & 2 & 2 & 4 & 8 \\
Rhipicephalus (Boophilus) sp. & 0 & 1 & 1 & 4 \\
Rhipicephalus evertsi evertsi & 7 & 3 & 10 & 16 \\
Rhipicephalus kochi & 0 & 1 & 1 & 4 \\
Rhipicephalus muehlensi & 13 & 4 & 17 & 32 \\
Rhipicephalus pravus & 21 & 23 & 44 & 52 \\
Rhipicephalus pulchellus & 85 & 49 & 134 & 92 \\
\hline Total & $\mathbf{2 1 0}$ & $\mathbf{1 5 2}$ & $\mathbf{3 6 2}$ & $\mathbf{1 0 0}$ \\
\hline
\end{tabular}

$n=25$.

TABLE 2: Ticks collected from African buffaloes in the Tsavo Conservation Area, Kenya.

\begin{tabular}{lllll}
\hline Tick species & Males & Females & Total & $\begin{array}{l}\text { Proportion } \\
\text { of animals } \\
\text { infested (\%) }\end{array}$ \\
\hline Amblyomma gemma & 121 & 18 & 139 & 46.8 \\
Amblyomma lepidum & 24 & 9 & 33 & 25.8 \\
Hyalomma albiparmatum & 15 & 0 & 15 & 9.7 \\
Hyalomma impeltatum & 3 & 0 & 3 & 1.6 \\
Hyalomma rufipes & 79 & 21 & 100 & 48.4 \\
Hyalomma truncatum & 2 & 1 & 3 & 3.2 \\
Rhipicephalus evertsi evertsi & 33 & 8 & 41 & 17.7 \\
Rhipicephalus humeralis & 17 & 9 & 26 & 22.6 \\
Rhipicephalus praetextatus & 7 & 1 & 8 & 6.5 \\
Rhipicephalus pravus & 0 & 1 & 1 & 1.6 \\
Rhipicephalus pulchellus & 537 & 165 & 702 & 66.1 \\
\hline Total & 838 & $\mathbf{2 3 3}$ & $\mathbf{1 0 7 1}$ & $\mathbf{1 0 0}$ \\
\hline
\end{tabular}

$n=62$. 
and 10 in 119 collections from buffaloes. In the present study, two cattle and two buffaloes were infested. H. truncatum was present on the upper perineum and tail of cattle and on the legs and tail of buffaloes. In addition to these attachment sites, Londt et al. (1979) recorded it from the lower perineum. The collection of $H$. truncatum in the Tsavo conservancy constitutes a new locality record for this species. The distance between this site and the closest locality recorded by Walker (1974) is approximately $250 \mathrm{~km}$.

The single female Rhipicephalus (Boophilus) sp. tick, collected from a cow, could not be identified to species level because of damage to its mouthparts. Walker (1974) reports two records of Rhipicephalus (Boophilus) sp. in the Tsavo region. OkeloOnen et al. (2001) collected ticks from cattle in the Kwale district, approximately $150 \mathrm{~km}$ to the southeast of the Tsavo Conservation area, and identified Rhipicephalus microplus on cattle in Kenya for the first time. They speculated that it may have been present along the Kenyan coast for some time but that it had not been detected there, or that it may have spread from the northern coastal region of Tanzania where it was known to exist (Yeoman \& Walker 1967). Rhipicephalus microplus is a cattle tick, but was not collected in the present study, indicating that it may not have spread inland.

Collections of Rhipicephalus evertsi evertsi from cattle and buffaloes were common. These findings support earlier data, which show that the preferred hosts of this tick are large animals such as cattle, elands (Taurotragus oryx) and zebras (Horak et al. 1991; Londt et al. 1979). Ticks collected from the cattle were attached in the upper perineum, whilst those from buffaloes were present on the upper and lower perineum and the tail, confirming the observations of Londt et al. (1979).

Collections of $R$. humeralis were made only from buffaloes and none from cattle. This differs from the records of Walker (1974), who reported 16 of 892 collections from cattle and only one from 119 buffaloes. Ticks were collected from the ears, neck, legs, upper and lower perineum. Judging by Walker's findings, this tick seems to prefer African elephants, Loxodonta africana, as hosts, of which she found 28 of 78 to be infested (Walker 1974).

A single specimen of $R$. kochi was collected from the cattle. Though not recovered from buffaloes during this study, it has previously been collected from these animals (Walker et al. 2000). Rhipicephalus muehlensi was collected from cattle and none from buffaloes, and the ears were the preferred site of attachment, confirming previous observations on nyalas (Tragelaphus angasii) by Horak, Boomker and Flamand (1995). Although no R. muehlensi was collected from buffaloes in this survey, or in the survey conducted by Walker (1974), it has been collected from these animals in other studies (Horak et al. 1983).

Rhipicaphalus praetextatus was collected only from buffaloes and none were found on cattle. When this tick does occur on cattle, infestations are usually light to moderate, whereas buffaloes are good hosts (Walker et al. 2000). Rhipicaphalus praetextatus was collected from the ear, neck, lower perineum and tail, with the greatest number of ticks collected from the tail. Because of confusion between the identification of this tick and Rhipicaphalus simus, Walker et al. (2000) indicated that all locality records for $R$. praetextatus prior to theirs in Kenya should be regarded as presumed. The present collections now confirm the presence of Rhipicaphalus praetextatus sensu stricto within the Tsavo Conservation Area. Walker (1974) recorded a few collections of Rhipicaphalus pravus sensu stricto from cattle in Kenya, and none from buffaloes. The single female tick collected from a buffalo in this study was attached to an ear, whilst ticks were attached to the ears, legs and lower perineum on the 13 infested cattle. This attachment pattern confirms earlier observations that Rhipicaphalus pravus may attach at several sites on the animal's body, including the dorsal surface of the ear and its base, the horn base, escutcheon, perineum, groin and heels (Yeoman \& Walker 1967).

Of all the tick species collected, Rhipicaphalus pulchellus was the most numerous on both cattle and buffaloes. R. pulchellus was present in all collection sites on cattle, with the highest numbers recovered from the ears, followed by the upper perineum and the tail. Similarly, ticks were collected from all sites on buffaloes, but on these animals most were present on the upper perineum followed by the tail, ears and the lower perineum. Similar records of $R$. pulchellus attaching in multiple sites have been noted for cattle, sheep and camels (Walker et al. 2000).

\section{Conclusion}

The aim of the study was to determine the ixodid tick species infesting cattle and buffaloes sharing the same habitat in the Tsavo Conservation Area, Kenya. Ticks were collected opportunistically from both host species and a total of 87 animals were sampled and 14 ixodid tick species recovered. Eight of these species, namely A. gemma, A. lepidum, $H$. albiparmatum, $H$. rufipes, $H$. truncatum, $R$. evertsi evertsi, $R$. pravus and $R$. pulchellus were collected from cattle and buffaloes. This finding indicates that not only ticks but also some of the diseases transmitted by ticks could be shared by these hosts, and that there is a need to establish the disease status of cattle and buffaloes in the area. In addition new locality records for $H$. impeltatum and $H$. truncatum were determined and the first locality record for $R$. praetextatus sensu stricto in Kenya is reported.

\section{Acknowledgements}

Kenya Wildlife Service Veterinary Department is thanked for administrative support and the staff of the department for their cooperation. We are grateful to Dr Maxime Madder for assistance with tick identification, Mayuko Koga, George Paul and Kingori Edward for their assistance in the field and to Paul Macharia for being a caring driver and Massai language translator in the field. This research was supported by grants from the National Research Foundation to BLP and IGH. 


\section{Competing interests}

The authors declare that they have no financial or personal relationship(s) which may have inappropriately influenced them in writing this paper.

\section{Author's contributions}

E.K.K. (Kenya Wildlife Service) collected and identified the ticks and wrote the first draft of the manuscript. B.L.P. (University of Pretoria) was responsible for planning the project and assisted with writing the manuscript. I.G.H. (University of Pretoria) assisted E.K.K. (Kenya Wildlife Service) with the identification of the more problematic tick species and assisted with the compilation of the manuscript.

\section{References}

Allsopp, B.A., Bezuidenhout J.D. \& Prozesky, L., 2004, 'Heartwater', in J.A.W. Coetzer \& R.C. Tustin (eds.), Infectious diseases of livestock, pp. 507-535, Oxford University Press Southern Africa, Cape Town.

Horak, I.G., Potgieter, F.T., Walker, J.B., De Vos, V. \& Boomker, J., 1983, 'The ixodid tick burdens of various large ruminant species in South African nature reserves', Onderstepoort Journal of Veterinary Research 50, 221-228. PMid:6646664

Horak, I.G., Fourie, L.J., Novellie, P.A. \& Williams, E.J., 1991, 'Parasites of domestic and wild animals in South Africa. XXVI. The mosaic of ixodid tick infestations on birds and mammals in the Mountain Zebra National Park', Onderstepoort Journal of Veterinary Research 58, 125-136. PMid:1923374
Horak, I.G., Boomker, J. \& Flamand, J.R.B., 1995, 'Parasites of domestic and wild animals in South Africa. XXXIV. Arthropod parasites of nyalas in north-eastern KwaZulu-Natal', Onderstepoort Journal of Veterinary Research 62, 171-179. PMid:8628570

Horak, I.G., 1999, 'Parasites of domestic and wild animals in South Africa. XXXVII. Ixodid ticks on cattle on Kikuyu grass pastures and in Valley Bushveld in the Eastern Cape Province', Onderstepoort Journal of Veterinary Research 66, 175184. PMid:10631707

Horak, I.G., Golezardy, H. \& Uys, A.C., 2007, 'Ticks associated with the three largest wild ruminant species in southern Africa', Onderstepoort Journal of Veterinary Research 74, 231-242. PMid:17933365

Lawrence, J.A., Perry, B.D. \& Williamson, S.M., 2004, 'Corridor disease', in J.A.W. Coetzer \& R.C. Tustin (eds.), Infectious diseases of livestock, pp. 468-471, Oxford University Press Southern Africa, Cape Town.

Londt, J.G.H., Horak, I.G. \& De Villiers, I.L., 1979, 'Parasites of domestic and wild animals in South Africa. XIII. The seasonal incidence of adult ticks (Acarina: Ixodidae) on cattle in the northern Transvaal', Onderstepoort Journal of Veterinary Research 46, 31-39. PMid:460821

Okello-Onen, J., Hassan, S.M., Essuman, S., Kariuki, D.P. \& Mbogo, S.K., 2001 'Boophilus microplus (Acari: Ixodida) reported for the first time in Kenya', Bulletin of Animal Health and Production in Africa 49, 146-149.

Tolvanen, R., 2004, 'Nature conservation areas in Kenya - Tsavo East and West National Parks', in P. Pellikka, J. Ylhaisi \& B. Clarks (eds.), Taita Hills and Kenya. Seminar, reports and journal of a field excursion to Kenya, pp. 59-63, Expedition reports of the Department of Geography, University of Helsinki.

Walker, J.B., 1960, Notes on the common tick species of East Africa, Cooper McDougal \& Robertson, Nairobi.

Walker, J.B., 1974, The ixodid ticks of Kenya: A review of present knowledge of their hosts and distribution, Commonwealth Institute of Entomology, London and Reading.

Walker, J.B. \& Olwage, A., 1987, 'The tick vectors of Cowdria ruminatum (Ixodoidea: Ixodidae, genus Amblyomma) and their distribution', Onderstepoort Journal of Veterinary Research 54, 353-379. PMid:3329325

Walker, J.B., Keirans, J.E. \& Horak, I.G., 2000, The genus Rhipicephalus (Acari, Ixodidae): A guide to the brown ticks of the world, Cambridge University Press, Cambridge. http://dx.doi.org/10.1017/CBO9780511661754

Yeoman, G.H. \& Walker, J.B., 1967, Ixodid ticks of Tanzania. A study of the zoogeography of the Ixodidae of an East African country, Commonwealth Institute of Entomology, London. 